\title{
The Effectiveness Of Using Virtual Reality Technology On Learning The Jump- Shot Skill in Basketball
}

\author{
Mohammad Shokri A. Zamzami \\ Faculty of Education, Physical Education Department, Umm Al-Qura University, Makkah, Saudi \\ Arabia \\ * Correspondence author. E-mail: zizotaif@ hotmail.com
}

\begin{abstract}
Received: 25 September 2020; Revised: 01 December 2020; Accepted: 05 December 2020 https://doi.org/10.24036/MensSana.050220.012
\end{abstract}

\begin{abstract}
This study aims to investigate the effectiveness of using Virtual Reality (VR) technology in learning the skill of jump-shot in basketball. Participants were 45 new volunteer students from the Department of Physical Education at Umm Al-Quran University. They had no experience in basketball and jump-shot in particular. They were divided into three groups, the control group, the real training group, and VR training group. Pre and post-tests were applied to the three groups to have a comparison between them. In the VR training group, we used the Virtual Reality headset device (HTC Vivek) to teach them the jump-shot in basketball. The scores were analyzed by using the One-Way ANOVA to measure their performance. Results showed a significant improvement in the level of performance for the jump-shot skill in the real training group and the VR group. While no significant improvement was noticed in the control group. Also, there were no significant differences between the real training and VR training group in post-test at the level of $\mathrm{p}=0.05$ in jump-shot for the basketball skill. The results motivated faculty members in colleges of physical education in Saudi universities to take advantage of modern technological means. Making it one of the new methods in teaching practical courses and conducting more research to identify the impact of using modern technology in learning.
\end{abstract}

Keywords: Virtual Reality-Basketball- Jump-Shot Skill

\section{INTRODUCTION}

Developments in technology in the $21^{\text {st }}$ century have increased by speeding the advancement of apps and software and making it easier to access all kinds of information. Currently, many new technologies particularly in the education sector are being applied to support the teaching and learning processes.

For example, the use of smart boards in classes and plagiarism detectors when students submit their homework are used today. The new generation of learners are highly capable of using computers and want to use innovative technology to facilitate the learning process through academic organizations and institutes.
Academic organizations and institutes, however, will face challenges when adopting emerging technologies. For instance, the high cost of electronic gadgets that will be used and the availability of good internet connection for students and teachers might be some of the challenges they face. To meet the demands of educational progress, effective approaches need to be employed.

The advancement of immersive and interactive technology in different learning and teaching styles may play an important supporting role (Abulrub et al.,2011). One of the innovations of technology that began to appear in the past few years is what is called Virtual Reality (VR).

VR can immerse individuals in an atmosphere that would normally be inaccessible 
because of cost, danger, or restrictions. Burdea and Coiffet (2003) defined VR as a simulation where computer graphics were used to create an environment that looked realistically and reacted to users' input. Also, VR can be defined as "the sum of the hardware and software systems that seek to perfect an all-inclusive, sensory illusion of being present in another environment" (Biocca \& Delaney, 1995).

A good VR environment delivers immersion, navigation, and manipulation for users (Hamit, 1993, Heim, 2000). There are many efficient VR applications in different fields such as entertainment, architecture, manufacturing, medicine, education, and training.

This environment is highly sought after for its versatility, reliability, and adaptability, especially in education and training (Alexandra, 2016).

Virtual Education (VE) is a modern revolution in the methods and techniques of education that harnesses the most recent technology findings from devices and programs in learning processes (Bascoul \&Amdilis, 2008).

Thus, VE integrates reality with imagination and creates an environment similar to the reality in which we move and live (Bascoul \&Amdilis, 2008). Therefore, it is necessary to apply this modern technology in developing education to serve both teachers and learners. VR is characterized by three basic characteristics which are interaction, cooperation, and experience (Fox et al., 2009).

In particular, VR is one technology that students find attractive. Virtual Reality is now commonly used in different areas of education and training (Abulrubet al., 2011), military training (Zyda, 2005), and medical and entertainment training (Stapleton et al., 2002). Moreover, VR has been applied to a broad range of sports such as skiing (Solina et al., 2008), goalkeeping rugby union (Brook, et al., 2007), baseball and basketball(Covaciet al., 2015), pistol shooting (Argelaguet et al., 2015), and cycling speed(Neumann et al., 2017). Indeed, the handball VR system for goalkeepers proved to be so successful that it was adopted by a national handball federation to train young national squad members and for talent identification (Bideau et al., 2003; Vignais et al., 2009).

The proposed simulator can be considered an excellent tool to increase the quality and speed of learning and developing motor skills and motor learning. Virtual Reality is a sophisticated system that utilizes and synthesizes different types of advanced high technology to produce a virtual world of multiple sense experience (Covaci et al., 2012).

The simulation model of education (the simulated world in education) has its benefits in terms of inspiring and engaging students and finding certain challenges for them. This allows students to study and role-play and to learn from the simulation world. By trial and error, this approach has an advantage, which is that the person doing the simulation sees the right result and hence reduces the error.

It is a good first impression, as well as taking human diversity into account as each student can explore the curriculum and solve problems and tests in their way. This has been shown in many studies that the use of simulation in the teaching of various science fields is effective and the student therefore quickly understands what suits him(Al-Ghareeb, 2009; Khaled, 2008 \&Shaqur, 2007).

Nowadays, if we look at the way sport skills are taught in the Physical Education Department at Umm Al-Qura University, we find students learn by the traditional method.

This method is based on the teacher giving the lecture while students listen without making enough effort to improve their level due to the limited time they have, in addition to the lack of equipment.

Basketball is one of the most interesting sports because it requires a lot of time and effort for the player to learn the skills and master them. Teams earn points in this sport by shooting the ball into the hoop. Therefore, shooting is a very 
important skill and directly influences the team's success (Button, Macleod, Sanders, \& Coleman, 2003).

The researcher found weaknesses in the player's basketball skills, especially in some basic skills that are characterized by a degree of difficulty and proficiency. Therefore, causing a decrease in learning outcomes(cognitive skill)including jump shot skill.

This was done by carefully observing the lessons of the educational process of basketball and comparing it to the learning outcomes by describing the approved courses in the general curriculum of the faculty of physical education.

The reason students have weaknesses in some of the basketball skills and difficulty in mastering them maybe because of the traditional methods that are being used in the learning process.

The ability to make a good jump shot gives players the following scoring advantages such as timing, speed, defense from an opponent, and the ability to release the ball from many distances from the basket (Okazaki \& Rodacki, 2012)

As a result, the jump shot has proved to be the most effective skill and the most employed shooting strategy, regardless of the position of the player on the team (Nunome et al., 2002). Figure (1) shows that jump-shot skill isa shot with one or both hands in which a player leaps into the air and shoots the ball at the basket at the moment of reaching the highest point of the leap (Victor et al., 2015).

Learning about the impact of virtual reality and how to use it in the stages of learning and education for some basketball skills, will help each a choice of an interactive educational method with innovative and influential technology in learning.

Subsequently, we can raise the level of student performance during the stages of learning. Therefore, this study aims to investigate the effectiveness of using virtual reality technology on learning the skill of jump-shot in basketball.

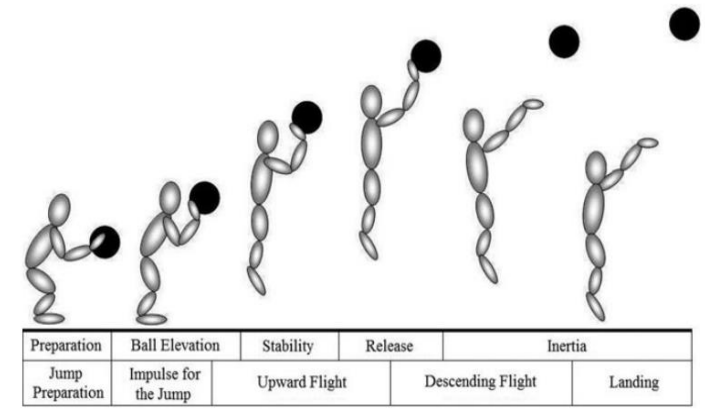

Figure 1 The stages of Jump-Shot

\section{Research aim:}

This study aims to investigate the effectiveness of using virtual reality technology on learning the skill of jump-shot in basketball.

\section{Research hypotheses:}

1. There are statistically significant differences between the pre and post-test of the control group in learning the skill performance of the jump-shots kill in basketball and in favor of post-test.

2. There are statistically significant differences between the pre and post-test of the real training group in learning the skill performance of the jump-shots kill in basketball and in favor of post-test.

3. There are statistically significant differences between the pre and post-test of the hypothetical training group in learning the skill performance of the jump-shot skill in basketball and in favor of post-test.

4. There are statistically significant differences between the two-dimensional measures of the groups (control - real training - virtual training) in learning the skill performance of the jump-shots kill in basketball.

\section{METHOD}

The experimental approach was using the experimental design of the groups (control - real training - virtual training). Pre and post-tests were used to have a comparison between the three groups. 


\section{Exploratory experience}

The researcher conducted an exploratory study in the basketball gym of the Physical Education Department at Umm Al-Qura University on 7 volunteer freshman students outside the basic research sample, and the exploratory experience aims to ensure:

-The validity of the three training programs of the application.

-The students' understanding of the methods used in the study.

-The validity of the devices and tools used.

carry out the research experiment.

- There are no obstacles that can occur during the experiment.

\section{Participants}

45 new volunteer students from the Department of Physical Education at Umm AlQura University in the year 1439-1440 (20182019) were randomly chosen, who had no experience in basketball in general and jump-shot in particular. All volunteers had a strong natural vision. Their average age is 18.71 years, and the average length is $174.84 \mathrm{~cm}$.

The Emotional Intelligence Scale was used to identify the consistency of the research sample from the mental side, the interaction with colleagues, the training environment, and the virtual reality device. It consists of five emotional dimensions (self-awareness, emotional management, motivation, human relations management, and empathy) measured through five levels of response (Aljanabi, 2011).

The researcher divided the research sample into 15 students as a virtual training (VR) group that learns by the virtual reality technique, 15 students as a real training (RT) group learns by the traditional way (verbal explanation provide a practical model - and practical implementation) and15 students as a control group who do not learn the selected skill.

Then apre-test jump-shot was done for the entire sample.

\section{Table (1) Research Sample}

\begin{tabular}{ccccc}
\hline Group & Weight & Length & Age & Intelligence \\
\hline \multirow{4}{*}{ All } & $65.667 \pm$ & & 18.71 & \\
& 6.620 & 174.844 & 1 & $65.844 \pm$ \\
& & \pm 4.079 & \pm 0.45 & 4.661 \\
& & & 8 & \\
Control & 68.067 & 175.200 & 0 & $66.000 \pm$ \\
& \pm 6.330 & \pm 4.507 & \pm 0.41 & 3.780 \\
& & & 4 & \\
Real & $63.467 \pm$ & 175.133 & 3 & $66.400 \pm$ \\
training & 7.029 & \pm 4.291 & \pm 0.45 & 5.235 \\
& & & 8 & \\
& 65.467 & & 18.60 & \\
VR & \pm 6.069 & 174.200 & 0 & $65.133 \pm$ \\
training & & \pm 3.590 & \pm 0.50 & 5.069 \\
& & & 7 & \\
\hline
\end{tabular}

\section{Apparatus}

The pre-test, post-test, and training were performed in the basketball gym. Participants used the official ball size and basketball tower in the Department of Physical Education at Umm Al-Qura University. To use the Virtual Reality technique in learning jump-shot in basketball, the virtual reality headset device(HTC Vive) was placed on a table 1.5 meter beside the throwing line on the basketball tower. This was done so that the virtual throws can be implemented in the same traditional educational environment.

The HTC Vive is an HTC and Valvedeveloped virtual reality headset (Figure 2). The headset uses gym scale tracking technology, allowing the person to move in $3 \mathrm{D}$ space and to use handheld controls with motion tracking to communicate with the environment. It requires a VR SHOOT AROUND application to perform the jump-shot skill during the study. VR SHOOT AROUND is an application that helps simulate the basketball shoot that can have spatial simulations, sounds, and a fantastic rich court. 


\section{System Requirement}

The computer has the following:

Operating system: Windows 10

Processor: Intel Core i5-4590

Memory: 4 GB RAM

Graphics: NVIDIA GeForce GTX 970

Storage: $250 \mathrm{MB}$ available space

\section{Study design}

Initially, participants conducted five throw runs to learn about the correct performance of the skill and get a feel of the learning environment and the gym on 1440/5/11. These throws were not recorded and were not part of the test. All participants received the same instructions for the technical steps to properly perform a jump-shot in basketball. All participants completed (20) throws on the real basketball tower, (10) throws during the pre-test in 1440/5/14 and (10) throws during post-test in 1440/6/9. The balls that went through the hoop were the only ones counted as correct.

\section{Training protocol}

During the period 1440/5/14-1440/6/9, pre and post-test sessions were conducted, the virtual training group received jump-shot training on the tower using the virtual reality device. The actual training group also received training in the gym by throwing the ball to the basketball tower using the technical steps. While the control group did not practice any training or was given any guidance at all. Each participant in a total of four weeks completed a training course consisting of 40 throws twice during one week for four weeks, which means that each participant threw 320 times.

\section{Data analyses}

Scores on all measures for the (control VR training- real training) groups were analyzed by repeated-measures One Way ANOVA.

\section{RESULT AND DISCUSSION}

\section{Result Research}

Table (2) ANOVA table between Control group- Real training- VR training pre-test

\begin{tabular}{cccccc}
\hline & $\begin{array}{c}\text { Sum of } \\
\text { Squares }\end{array}$ & df & $\begin{array}{c}\text { Mean } \\
\text { Square }\end{array}$ & F & Sig. \\
\hline $\begin{array}{c}\text { Between } \\
\text { Groups }\end{array}$ & 0.844 & 2 & 0.422 & 0.455 & 0.637 \\
$\begin{array}{l}\text { Within } \\
\text { Groups }\end{array}$ & 38.933 & 42 & 0.927 & & \\
Total & 39.778 & 44 & & & \\
\hline $\mathrm{F}(2,44)=3.21, \mathrm{p}=0.50$ & & & &
\end{tabular}

The results for the analysis of variance in a table (2) revealed no significant differences between the (control - VR training- real training) groups in pre-test for the jump-shot basketball skill accuracy, $\mathrm{F}(2,44)=3.21, \mathrm{p}=0.50$.

Table (3) ANOVA table between Control groupReal training- VR training post-test

\begin{tabular}{cccccc}
\hline & $\begin{array}{c}\text { Sum of } \\
\text { Squares }\end{array}$ & df & $\begin{array}{c}\text { Mean } \\
\text { Square }\end{array}$ & F & Sig. \\
\hline $\begin{array}{c}\text { Between } \\
\text { Groups }\end{array}$ & 130.133 & 2 & 65.067 & 33.058 & 0.000 \\
Within & 82.667 & 42 & 1.968 & & \\
$\begin{array}{c}\text { Groups } \\
\text { Total }\end{array}$ & 212.800 & 44 & & & \\
\hline $\mathrm{F}(2,44)=3.21, \mathrm{p}=0.50$ & & & & \\
\hline
\end{tabular}

The results for the analysis of variance in a table (3) revealed significant differences between the (control- VR training- real training) groups in post-test for the jump-shot basketball skill accuracy, $\mathrm{F}(2,44)=3.21, \mathrm{p}=0.50$.

Table (4) LSD between groups Control- Real training- VR training post-test

\begin{tabular}{|c|c|c|c|c|}
\hline Groups & Mean & Control & $\begin{array}{c}\text { Real } \\
\text { training }\end{array}$ & VR training \\
\hline Control & 3.8667 & & $3.73333^{*}$ & $3.46667 *$ \\
\hline $\begin{array}{l}\text { Real } \\
\text { training }\end{array}$ & 7.6000 & & & 0.26667 \\
\hline $\begin{array}{l}\mathrm{VR} \\
\text { training }\end{array}$ & 7.3333 & & & \\
\hline
\end{tabular}

Table (4) shows the real training group and the VR training groups improved between pre and post-tests, $\mathrm{F}(2,44)=3.21, \mathrm{p}=0.50$, while 
the control group did not show a recognizable improvement in jump-shot for the basketball skill.

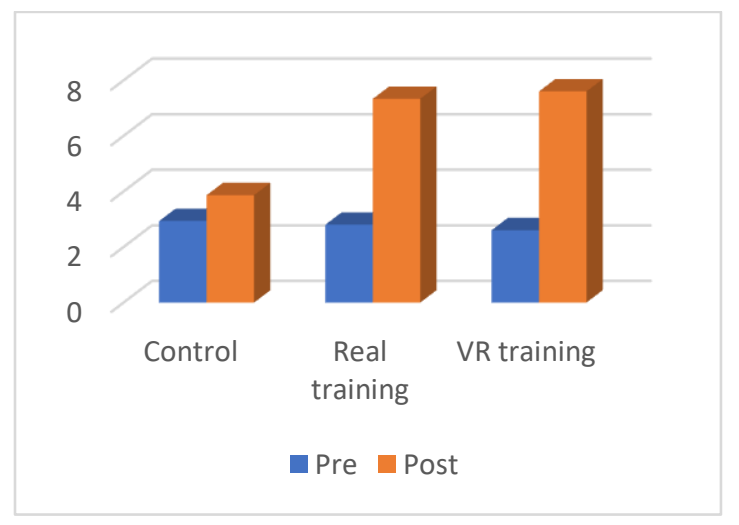

Figure 3demonstrates the interaction of groups and testing the jump-shot basketball skill throwing accuracy in both conditions combined.

Table (5)the post-hoc LSD between-group Control- Real training- VR training post-test

\begin{tabular}{cccc}
\hline Groups & Pre & Post & $\%$ \\
\hline Control & 2.9333 & 3.8667 & 31.82 \\
$\begin{array}{c}\text { Real } \\
\text { training } \\
\text { VR } \\
\text { training }\end{array}$ & 2.6000 & 7.6000 & 192.31 \\
\hline
\end{tabular}

Table (5) indicates, there is a significant difference between the three groups in favor of the real training group at the level of $\mathrm{p}=0.05$. There is no significant difference between the real training group and VR training group in the post-test at the level of $\mathrm{p}=0.05$ in jump-shot for the basketball skill.

Table (6) T-Test between Pre and Post Test for (Control group- Real training- VR training)

\begin{tabular}{ccccc}
\hline Groups & $\begin{array}{c}\text { Differences } \\
\text { Mean }\end{array}$ & $\mathrm{t}$ & $\mathrm{df}$ & $\begin{array}{c}\text { Sig. } \\
(2- \\
\text { tailed })\end{array}$ \\
\hline $\begin{array}{c}\text { Control } \\
\text { Real } \\
\text { training } \\
\text { VR }\end{array}$ & 0.9334 & 2.064 & 14.000 & 0.058 \\
$\begin{array}{c}\text { training } \\
\mathrm{T}=2.000\end{array}$ & $13.693^{*}$ & 14.000 & 0.000 \\
\hline $\mathrm{T}=2.5533$ & $8.646^{*}$ & & \\
\hline
\end{tabular}

In the table (6), there are no significant differences in jump-shot for the basketball skill between the pre-test and the post-test for the control group, while there are significant differences between the pre-test and the post-test for the real training group and the VR training group in favor of the post-measurement, at the level of, $\mathrm{T}=2.145, \mathrm{p}=0.50$.

\section{Discussion}

The first hypothesis was that the control group will lead to statistically significant results and better skill performance; however, the results showed no significant differences between the pre-and post-test for the jump-shot skill in basketball. This result is because the participants did not have practice or demonstration for the jump-shot skill during the study period.

The second hypothesis was that the real training group will lead to statistically significant results and better skill performance. The results did show significant differences between the preand post-test for the skill performance of the jump-shot skill in basketball. This result is because the participants have had enough time to practice and were demonstrated how to do the jump-shot skill during the study period. This indicates that the traditional method is useful to teach a jump-shot skill. Traditional education is still effective and has an impact on some educational areas that require the learner to obtain feedback from the teacher directly (Abbas, 2013).

The third hypothesis was that the VR training group will lead to statistically significant results and better skill performance. The results did show a significant difference in ATP $(0.5)$ between the pre-and post-test for the skill performance of the jump-shot skill in basketball.

This result is because participants have had time to use virtual reality technology to learn jump-shot skills during the study period. This means that using VR technologies useful to teach a jump-shot skill. These results show the efficiency of our training intervention not only on 
motor learning and performance but also on the interacting perceptual processes (Schorer et al., 2015).

The fourth hypothesis considered the significant differences between the twodimensional measures of the groups (control real training - virtual training) in learning the skill performance of the jump-shot skill in basketball. In tables $(3,4,5)$ and figure (3), the researcher attributes the differences between the three groups(control, real training, and the virtual training) in favor of the real training group in the skill of jump-shot to the extent of interaction of participants with the teacher and peers in the traditional way using real basketballs and the gym.

After that, we found improvement for the virtual training group in the skill of jump-shot and that refers to the interaction of students with the use of virtual reality technology in a way to learn basketball skills. While the control group did not have a chance to learn from a teacher or use modern technology. In table (5) data shows that there are no significant differences between the real training group and VR training group in post-test at the level of $\mathrm{p}=0.05$ in jump-shot for the basketball skill. This indicates that both the real and the VR training can improve participants.

Educators can merge these two ways to have better new teaching methods to learn motor learning and movement performance skills. In fact, Abbas (2013) announced that traditional and new learning methods are very consistent and differ in the means. The purpose of these two types of education is to obtain high-level outputs characterized by advanced knowledge and good qualification.

From table (6) researchers perceived that the use of VR technology was raising students' motivation for achievement and success because virtual reality attracts the attention of students, helps them to gain motor experiences, learn from personal mistakes, and use new ways to learn. All these experiences are integrated through VR technology.

Also using VR helps to achieve the desired goals efficiently and effectively through sequential images, slow and fast threedimensional videos that explain the typical performance of the skills to be learned and provide a stereoscopic vision. This is consistent with the employment of virtual reality technology that contributes effectively to making a great interaction between the student and the educational content of the program, especially in academic subjects that require real-life experience but is difficult to achieve, so this type of technology is the best means(Schorer et al., 2015), (Alexander et al.,2016).

Indeed, in a table (6) the researcher explains the differences between the pre and post measurements of the real training group in favor of the post measurements as a result of applying the traditional educational program followed. As it is not possible to overlook the traditional method, which depends on the verbal explanation of the motor skill to be learned and provide a practical model by one of the students or the teacher for the skills.

Practice and repetition by the learner with correcting mistakes from the teacher positively affect the efficiency of the performance level. It is also an indication that the program followed has a positive impact on the learning process, and this allows the opportunity to learn properly and also provide the knowledge and information accompanying when learned skills during the educational units have helped to increase the knowledge and student information(Alexander et al.,2016; Lin et al.,2011). Based on the previous results and literature review, this study will present and discuss the benefits of VR for educational purposes, specifically for teaching student's movement skills.

Implementing VR in education will offer tremendous benefits such as promoting and 
enhancing teaching and learning processes. In a general educational context, several research studies have explored the efficacy of various learning strategies, but fewer studies have explored the effects of VR on education (Thorsteinsson et al., 2010). However, several experiments were performed to examine the usefulness of VR as an instructional tool (Winn, 1993).

Students should exchange their ideas in groups, share perspectives, and collaborate in a collaborative/cooperative environment while acquiring information during their learning process (Dimitropoulos et al., 2008). Taxén and Naeve (2002), therefore, suggested that teachers needed to change their teaching methods to the VR environment.

VR applications that enable interactive learning have significant advantages in collective and cooperative learning for social experiences (Hodge et al., 2008). Collaborative learning experiences often promote strategic thoughts, allowing learners to improve problem-solving skills. So, these environments also foster greater participation between learners (Dimitropoulos et al., 2008). A shared VR atmosphere will, thus, be a valuable resource for promoting learning processes.

VR will play a significant role in promoting and enhancing innovative thinking for students. The creative component of VR in particular will encourage learners to improve their ability to solve problems, particularly openended problems. Innovative simulation is one of the strategies that will help learners grow their creativity and help consumers explore topics of interest in the VR world.

For example, Sims (2007) implemented interactive learning and role-playing to enhance the memory and morale of the learners in a VR learning environment. As a result, VR technology needs more recognition as a teaching resource to promote innovation from educators as well as policymakers, because it can explicitly help the imagination of learners in different ways.
Finally, applying Virtual Reality technologies to physical education in Saudi education is considered a brand new idea. In modern physical education, the standard form of instruction is now followed by most colleges. Some schools have begun using digital technology in teaching while others have adopted the technology of Virtual Reality. However, Virtual Reality technology is not yet mainstream because of the relatively high hardware device prices.

As a modern educational tool, we must understand the teaching opportunities and tremendous promise of Virtual Reality technology. Liao (2015) claims that the VR introduced to physical education should be seen as a jump in physical education's technical growth. It will bring in interactive scenes and build an individual learning experience.

Not only can VR save time for training, it can also show clear and practical effects. Therefore, students will develop their selftraining knowledge and capacity to innovate, especially in preventing injury during physical lessons, compensating for bad situations, creating virtual characters, overcoming room and time constraints, and helping to unlock talent in school. The use of VR technologies in physical education can make athletic methods incredibly exciting and gain prominence such that the physical training approach becomes more detailed.

\section{CONCLUSION}

The traditional method (verbal explanation and model performance) has a positive effect on learning basketball skills in general and the jump-shot in particular for the real training group. VR has a positive effect on learning basketball skills in general and the jump-shot in particular for the experimental group.

The percentage of improvement in the level of performance of the jump-shot skill for the real training group and the VR group was 
much better than the rate of improvement of the control group that did not practice the selected skill.

The results of the study proved the effectiveness of the virtual reality method in stimulating and focusing students to use the maximum extent of their abilities to reach the optimal performance of the jump-shot in basketball.

The educational program prepared using virtual reality was good enough for the traditional method (verbal explanation and model performance) for learning the skills of the jumpshot in basketball.

\section{Recommendations}

Based on what the results indicated and the findings, the researcher recommends the following; Using modern technological means to learn basketball skills because of its positive impact in learning jump-shot and the technical aspects related to it.

Carrying out similar studies on different sporting activities and at various age, stages to keep pace with the development occurring in developed countries and raise practical and educational efficiency and work to produce much virtual reality software in other sports activities in cooperation with experts and specialists in educational technology.

The use of modern technological means in teaching practical approaches in particular and theoretical approaches in general in the field of physical education for the effectiveness of this method and the confirmation of many previous studies on its effectiveness.

Urging the faculty members of the colleges of physical education in Saudi universities to take advantage of modern technological means as one of the specific methods in teaching practical courses and conduct more research to identify the impact of the use of modern technology in learning.
The necessity of conducting training courses for teachers and faculty members to train them to use modern technological means in teaching.

\section{CITATIONS AND REFERENCES}

Abulrub, A. H. G., Attridge, A. N., \& Williams, M. A. (2011). Virtual reality in engineering education: The future of creative learning. Paper presented at the 2011 IEEE Global Engineering Education Conference (EDUCON).

Abbas, Zaki. (2013). The role of e-learning in educational institutions compared to traditional education - an applied study at the Technical Institute in Diwaniyah. The Iraqi Magazine For Managerial Sciences, Karbala University.

Argelaguet Sanz, F., Multon, F., \& Lecuyer, A. (2015). A methodology for introducing competitive anxiety and pressure in VR sports training. Front. Robot. AI 2(10).

Alexandra Covaci, Cristian-Cezar Postelnicu, Alina Panfir, Doru Talaba. (2016). A Virtual Reality Simulator for Basketball Free-Throw Skills Development. HAL Id: hal-01365575, https://hal.inria.fr/hal01365575

Al-Ghareeb, Zahir. (2009). Electronic Courses", Arab Thought Center, Cairo.

Aljanabi, Amjad. (2011). The effect of a training program "based on the Daniel Coleman model" in developing emotional intelligence skills for high school students, Master Thesis, College of Education, Ibn Rushd.

Bascoul, P.D., Amdilis, B. (2008). AL Virtual reality, which contribution for machine $\mathrm{AC}$ - design in students product engineering, tools and methods based on virtual reality Springer science business media B.V.2008.

Bideau, B., Kulpa, R., Ménardais, S., Fradet, L., Multon, F., Delamarche, P. (2003). Real 
handball goalkeeper vs. virtual handball thrower. Presence 12, 411-421.

Biocca F., Delaney B. (1995). Immersive virtual reality technology Communication in the age of virtual reality, Lawrence Erlbaum Associates, Inc, Hillsdale.

Brook, P., Croft, H., \& Mann, S. (2007). Laserbased lineout simulator. In Mann, S. \& Bridgemean, N, (Eds.), Proceedings of the 20th Annual Conference of the National Advisory Committee on Computing Qualification, Nelson, New Zealand.

Button, C., Macleod, M., Sanders, R., \& Coleman, S. (2003). Examining movement variability in the basketball free-throw action at different skill levels. Research Quarterly for Exercise and Sport, 74, 257269.

doi:10.1080/

02701367.2003.10609090

Covaci, A., Postelnicu, CC., Talaba, D. (2012) A Virtual Reality Simulator for Basketball Free-Throw Skills Development, in Proceedings of the 3rd Doctoral Conference on Computing, Electrical and Industrial Systems, Caparica, Portugal, February 2012

Covaci, A., Olivier, A. H., \& Multon, F. (2015). Influence of visual perspective and feedback guidance for free throw training in virtual reality. Virtual Reality Software and Technology, 79-82.

Dimitropoulos, K., Manitsaris, A., \& Mavridis, I. (2008). Building virtual reality environments for distance education on the web: A case study in medical education. International Journal of Social Sciences, 2(1), 62-70

Fox, J,Arena, D\&Bailenson, J (2009). Virtual reality, Asurvival guide for the social Scientist, journal of media psychology, v. 21, N3, 2009.

Hamit, F. (1993). Virtual reality and exploration of cyberspace: Sams
Heim, M. (2000). Virtual Realism, 1st end. Oxford University Press, Inc.,

Hodge, E. M., Tabrizi, M., Farwell, M. A., \& Wuensch, K. L. (2008). Virtual reality classrooms: Strategies for creating a social presence. International Journal of Social Sciences, 2(2), 105-109.

Khaled, Jamila (2008). The effect of using a hypothetical learning environment in science education on the achievement of a sixth-grade basic application in UNRWA schools in Nablus Governorate, MA, Thesis, An-Najah National University, Nablus, Palestine

Lin Zhang, and Ling Wang. (2011). VR-Based Basketball Movement Simulation, Transactions on Edutainment V, LNCS 6530, pp. 240-250, 2011. Springer-Verlag Berlin Heidelberg

Liao, ting. (2015). Application of Virtual Reality Technology to Sports. International conference on Circuits and systems. Wuhan Sports University.

Neumann DL, Moffitt RL, Thomas PR, Loveday K, Watling DP, Lombard CL, Antonova S, Tremeer MA. A. (2017). systematic review of the application of interactive virtual reality to sport. Virtual Real.

Nunome, H., Doyo, W., Sakurai, S., Ikegmai, Y., \& Yabe, K. (2002). A kinematic study of the upper-limb motion of wheelchair basketball shooting in tetraplegic adults. Journal of Rehabilitation Research and Development, 39, 63-71.

Okazaki, V. H. A., \& Rodacki, A. L. F. (2012). Increased distance of shooting on basketball jump shot. Journal of Sport Science and Medicine, 11, 231-237.

Schorer, J., Rienhoff, R., Loffing, F., \& Hagemann, N. (2015). Efficacy of training interventions for acquiering perceptual cognitive skill. In J. Baker \& D. Farrow (Eds.), Routledge Handbook of Sport Expertise. London: Routledge. 
Shaqur, Ali (2007). The level of assessment of male and female science teachers in UNRWA schools in Nablus governorate for simulated virtual laboratories in the educational process, unpublished research, An-Najah National University, Nablus, Palestine

Sims, E. M. (2007). Reusable, lifelike virtual humans for mentoring and role-playing. Computers \& Education, 49(1), 75-92. Available at: https://doi.org/10.1016/j.compedu.2005.06. $\underline{006}$.

Solina, F., Batagelj, B., \& Glamočanin, S. (2008). "Virtual skiing as an art installation," in ELMAR, 2008. 50th International Symposium (Zadar: IEEE), 507-510.

Stapleton, C., Hughes, C., Moshell, M., Micikevicius, P., \& Altman, M. (2002). Applying mixed reality to entertainment. Computer, 35(12), 122-124.

Taxén, G., \& Naeve, A. (2002). A system for exploring open issues in VR-based education. Computers \& Graphics, 26(4), 593-598. Available at: https://doi.org/10.1016/s0097$\underline{8493(02) 00112-7 .}$

Thorsteinsson, G., Page, T., \& Niculescu, A. (2010). Using virtual reality for developing design communication. Studies in Informatics and Control, 19(1), 93-106. Available at: https://doi.org/10.24846/v19i1y201010.

Victor H.A. Okazaki, André L.F. Rodacki \& Miriam N. Satern (2015): A review onthe basketball jump shot, Sports Biomechanics, DOI: 10.1080/14763141.2015.1052541

Vignais, N., Bideau, B., Craig, C., Brault, S., Multon, F., \& Kulpa, R. (2009). Virtual environments for sport analysis: perception-action coupling in handball goalkeeping. International Journal Virtual Reality. 8(1), 43-48.

Winn, W. (1993). A conceptual basis for educational applications of virtual reality. Technical Publication R-93-9, Human Interface Technology Laboratory of the Washington Technology Center. Seattle: University of Washington.

Zyda, M. (2005). From visual simulation to virtual reality to games. Computer, 38(9), 25-32. Available at: https://doi.org/10.1109/mc.2005.297. 